\title{
Focused Ion Beam-induced Ripple and Nanoparticle Formation in $\mathrm{Cd}_{2} \mathrm{Nb}_{2} \mathrm{O}_{7}$
}

\author{
Jie Lian, ${ }^{*}$ Wei Zhou, ${ }^{* *}$ Lumin Wang, ${ }^{*}$ L. A. Boatner ${ }^{* * *}$ and Rodney C. Ewing ${ }^{*}$ \\ *Departments of Geological Sciences and Nuclear Engineering \& Radiological Sciences, University \\ of Michigan, Ann Arbor, MI 48109, USA \\ **School of Mechanical and Aerospace Engineering, Nanyang Technological University, Singapore \\ 639798 \\ *** Oak Ridge National Laboratory, Oak Ridge, TN 37831-6056, USA
}

Ion beam techniques have been widely used for the fabrication of novel nanostructures by implantation, phase-decomposition and order-disorder phase transition processes. The formation of periodic ripple or a wavelike structure with a spatial wavelengths varying from $\mathrm{nm}$ to $\mu \mathrm{m}$ scale has been observed in many ion beam-bombarded solid surfaces and is believed to be caused by the competition between a roughening process as a result of ion beam sputtering (erosion) of surface and a smoothening process induced by thermal or ion-induced surface diffusion. Recently, ion sputtering-induced ripple structures have been of particular interest for the fabrication of nanoscaletextured materials via self-organization processes or as templates for the growth of nanowires, nanorods and nanodots. Here, we report the simultaneous formation of a ripple structure with the characteristic wavelength varying from $\mathrm{nm}$ to sub- $\mu \mathrm{m}$ range induced by ion sputtering and the formation of uniformly-distributed metallic nanoparticles with the size of $3 \sim 10 \mathrm{~nm}$ caused by ion irradiation-induced phase decomposition. Ion sputtering experiments were performed on a $\mathrm{Cd}_{2} \mathrm{Nb}_{2} \mathrm{O}_{7}$ single crystal using FSEM/FIB dual beam system (FEI Nova 200 NanoLab). A focused $\mathrm{Ga}^{+}$beam with an energy of $30 \mathrm{keV}$ was used for ion sputtering at beam currents from $10 \mathrm{pA}$ to $5 \mathrm{nA}$ at different incident angles. The surface morphology and microstructural evolution upon ion sputtering were characterized by in-situ SEM, ex-situ AFM and TEM techniques.

A ripple structure perpendicular to ion projection directions can be induced on $\mathrm{Cd}_{2} \mathrm{Nb}_{2} \mathrm{O}_{7}$ substrate by $\mathrm{Ga}^{+}$ion sputtering at an incident angle varying from $30^{\circ}$ to $50^{\circ}$. The characteristic wavelength of the ripple structure formed at a high dose of $4.01 \times 10^{18}$ ions $/ \mathrm{cm}^{2}$ measured from the in-situ SEM image (Fig. 1A) is $\sim 350 \mathrm{~nm}$, and the surface roughness of the ripple structure was determined to be $\sim 35 \mathrm{~nm}$ from the AFM image (Fig. 1B). By varying the ion flux and the incident angles, the characteristic wavelength of the ripple structure can be controlled from $\sim 130 \mathrm{~nm}$ to $620 \mathrm{~nm}$. Ripples were patterned at different areas of a $\mathrm{Cd}_{2} \mathrm{Nb}_{2} \mathrm{O}_{7}$ thin foil for TEM observation in order to characterize the ripple microstructure. Fig. 2A shows a high angle annular dark field STEM image of the ripple structure patterned with $30 \mathrm{keV} \mathrm{Ga}^{+}$at an ion dose of $6.27 \times 10^{16}$ ions $/ \mathrm{cm}^{2}$. The wavy-like contrast resulting from the variation of the sample thickness clearly demonstrated the formation of a ripple structure. The EDS line profile across the ridge of a ripple, as marked by a white line of Fig. $2 \mathrm{~A}$, indicates that the ridge of the ripple contains more $\mathrm{Nb}$ and $\mathrm{O}$. This result suggests that surface diffusion of $\mathrm{Nb}$ and $\mathrm{O}$ might play an important role in the formation of ripples. No significant variation has been observed in the average signals of Cd (EDS profile); in contrast, uniformlydistributed nanoparticles, 3 10 nm, were observed in the $\mathrm{Ga}^{+}$sputtered $\mathrm{Cb}_{2} \mathrm{Nb}_{2} \mathrm{O}_{7}$, as evidenced in the Z-contrast image (Fig. 2B). EDS maps (inset in Fig. 2B) show that the nanoparticles are Cd-rich, but depleted in $\mathrm{Nb}$ and $\mathrm{O}$. A bright-field TEM image (Fig. 3A) shows the morphology of nanoparticles formed in $\mathrm{Ga}^{+}$sputtered $\mathrm{Cd}_{2} \mathrm{Nb}_{2} \mathrm{O}_{7}$. The $\mathrm{Nb}$-depleted feature of nanoparticles is further evidenced by the $\mathrm{Nb}$ map formed by energy loss electrons (Fig. 3B). The nanoparticles were identified as pure $\mathrm{Cd}$ metal nanoparticles by indexing the ring pattern (inset in Fig. 3A) and the lattice spacing of the nanoparticles (Fig. $3 \mathrm{C}$ ). The formation of $\mathrm{Cd}$ metal nanoparticles was induced by the phase decomposition process of $\mathrm{Cd}_{2} \mathrm{Nb}_{2} \mathrm{O}_{7}$ single crystals upon $\mathrm{Ga}^{+}$ion irradiation, 
concurrent with the formation of the self-organized ripple structure. This work was supported by the DOE Office of Basic Energy Sciences (DE FG02 97 ER45656) and an NSF NIRT grant (EAR0403732).
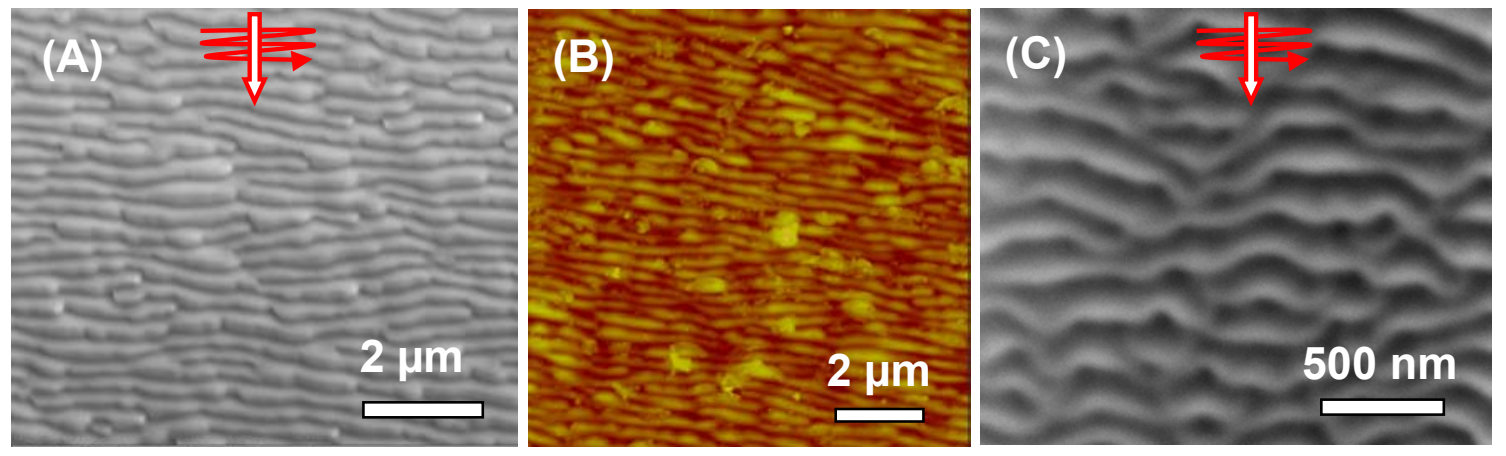

Fig. 1 (A) SEM and (B) AFM images of coarse ripples formed on $30 \mathrm{keV} \mathrm{Ga}{ }^{+}$sputtered $\mathrm{Cd}_{2} \mathrm{Nb}_{2} \mathrm{O}_{7}$ (at an incidence angle of $50^{\circ}$ and a high dose of $4.01 \times 10^{18}$ ions $/ \mathrm{cm}^{2}$ ). (C) SEM image of finer ripples formed at a lower dose of $6.27 \times 10^{16}$ ions $/ \mathrm{cm}^{2}$. The straight arrow indicates the projected ion beam direction and curved arrow shows the fast-scan direction.
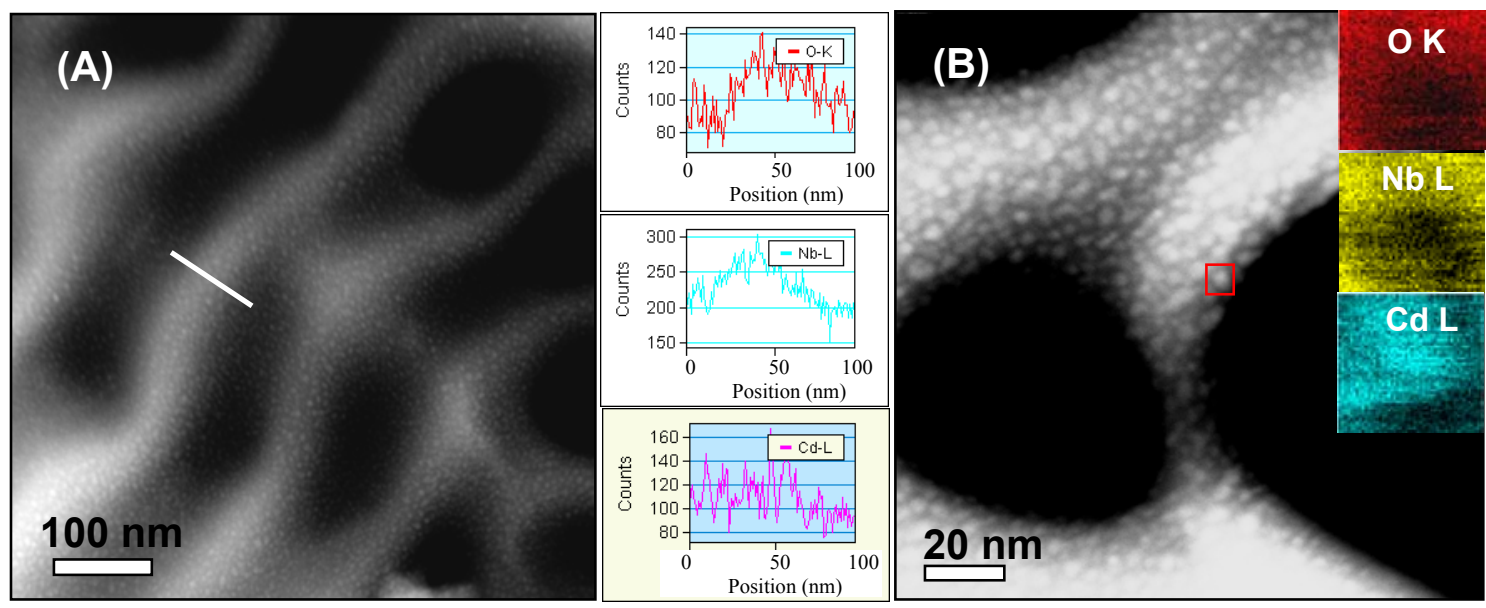

Fig. 2 HAADF-STEM images show the ion sputtering-induced ripples (A) and ion irradiationinduced nanoparticle formation (B) in $\mathrm{Cd}_{2} \mathrm{Nb}_{2} \mathrm{O}_{7}$ at a dose of $6.27 \times 10^{16}$ ions $/ \mathrm{cm}^{2}$. Insets of Figs. $2 \mathrm{~A}$ and $2 \mathrm{~B}$ are EDS profile and elemental mapping, respectively.
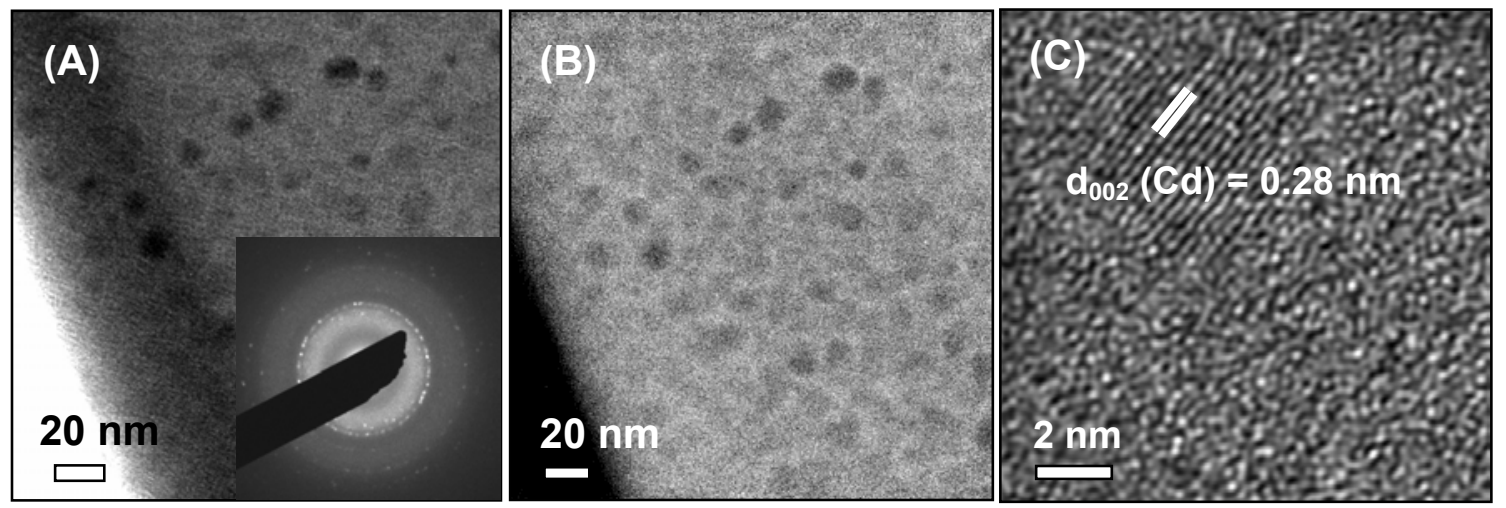

Fig. 3. (A) A bright-field TEM image and the corresponding $\mathrm{Nb}$ elemental map formed by energyloss electrons. Inset in Fig. 3A is the electron diffraction pattern of nanoparticles. (C) Highresolution TEM image of a $\mathrm{Cd}$ nanoparticle. 